\title{
Theoretical Approaches to the Study of Voting Behaviour: A Comparative Analysis
}

\author{
* Noor Hamid Khan Mahsud, PhD Scholar \\ ** Husnul Amin, Fulbright Fellow South Asia Center
}

\begin{abstract}
The study of voting behaviour is a sub-field of Political Science. Voting represents an important aspect of public participation in a democratic system. Keeping in view the importance of voting behaviour in a democratic dispensation, social scientists have paid much attention to its determinants. At least three kinds of theoretical models can be discerned in the works of social scientists: a sociological model, a psycho-social model, and a rational choice model. The focus of the sociological model is on social factors, the psychosocial model focuses on psychological or political factors, while the rational choice model emphasizes economic factors. The main aim of the paper is to present a brief overview of these three kinds of models comparatively.
\end{abstract}

Keywords: Voting Behaviour, Sociological Model, Psychosocial Model, Rational Choice Model Introduction

The modern history of the academic study of voting behaviour started just before the 1940 American presidential elections when a team of researchers led by the Austrian-American sociologist Paul Lazarsfeld (Columbia University) started using survey research for the scientific study of voting behaviour (Bartels, 2010). Since then, researchers in the field of electoral studies have come forward with various explanations about the determinants of voting behaviour. Some of these explanations received more attention than others and have accentuated heated academic debate in the academic community engaged in the analysis of voting behaviour (Hutchings \& Jefferson, 2018).

This paper focuses on only three major theoretical approaches to the scientific study of voting behaviour. These include: the sociological model, which is also known as the School of Columbia; the psychosocial approach also known as the School of Michigan, and; the Rational Choice Theory approach also called the School of Rochester or model of economic voting (Antunes, 2010 \&Antwi, 2018). These models have their origins in the disciplines of sociology, psychology, and economics, respectively (Visser, 1998). In this paper, the researchers present a detailed overview of all the three theoretical models.

\section{The Sociological Model (Columbia School of Voting Behaviour)}

In 1939, the discipline of psychology entered the field of election studies when Paul Lazarsfeld along with other colleagues at Columbia University planned a systematic study of presidential elections of 1940 in Erie County (Visser, 1994) of New York State. This pioneering study explaining factors influencing individuals' voting decisions was the first to be based on survey methods and compiled in the form of a book titled: "The People's Choice: How the Voter Makes Up His Mind in a Presidential Campaign." This study conducted by scholars at Columbia University's Applied Bureau of Social Research ultimately led to the emergence of the sociological model of voting behaviour also known as the Columbia Model of voting behaviour (Antunes, 2010; Hutchings \& Jefferson, 2018). The basic assumptions of this model are explained in three major works: "The People's Choice: How the Voter Makes up His Mind in a Presidential Campaign," Voting: A Study of Opinion Formation in a Presidential Campaign," and "Personal Influence: The Part Played by People in the Flow of Mass Communications," published in 1944, 1954, and 1955, respectively (Antunes, 2010).

This theory of voting behaviour focuses on the individual and the social structure surrounding the individual. Thus, it places votes in social context and then studies the effects of variables such as social class, religion, nationalism, language, and rural-urban divisions (Scott \& Marshall, 2009;

\footnotetext{
* Department of Politics and IR, International Islamic University Islamabad Email: nhkmaseed22@gmail.com

** University of Pennsylvania, United States
} 
Hutchings \& Jefferson, 2018; Antwi, 2018). According to this theory, individuals learn their partisan predilections corresponding to the political orientations of the group to which they belong. (Aiba, 2003).

The Columbia team of researchers selected a panel of 600 respondents whom they interviewed seven times before the elections (Bartels, 2010). One of the goals of this study was to ascertain the impact of mass media on voters' decision-making process. The results shocked the researchers as 546 out of 600 respondents had already made their voting decisions even before the campaign could be started. Thus the research team in its analysis puts more emphasis on external factors, especially the influence of voters' primary groups. According to the findings of this study, voting decisions are determined by social forces. The researchers found that social groups' active members (opinion-makers) interposed between the media content and the members of the social groups, thus disseminating the media messages in the less involved (less active) group members in a way congenial to the political standards of the group members (Visser, 1994). Furthermore, the research team found that voters selectively viewed media messages to filter propaganda which contradicted their own opinions, so there was little room for political parties to attract voters toward themselves through election campaigns (Visser, 1998).

Contrary to the hypothesis that voting decisions were influenced by voters' personality and media, the research team discovered that social groups to which voters belonged played a decisive role in voters' decision-making process. The investigators argued that the relationship between voting behaviour and voters' social groups was so strong that voters' choices could be explained by just focusing on three elements: religion, socio-economic class or status, and place of residence. The combination of these three was termed as "Index of Political Predisposition" (IPP). It argued that instead of election campaigns and debates on issues by the candidates, the undecided voters or those who changed their mind during the campaign were pressurized by their fellow social group members to vote for a particular candidate (Antunes, 2010).

The Columbia team found that the media content played an insignificant role in changing voters' choices as most of these choices were rooted in strong loyalties of social class and religion reinforced by interactions with like-minded acquaintances (Bartels, 2010). It argued that the two effects of the election campaign were the reinforcement of choices made by earlier deciders and the motivation of latent predispositions of uncommitted voters. The researchers claimed that these predispositions activated by the electoral campaigns were linked with social characteristics called IPP (Hutchings \& Jefferson, 2018).

Researchers as Columbia University conducted another study in the Elmira community in New York in 1948 and the findings of this study were published in 1954 in the shape of another influential work titled Voting: A Study of Opinion Formation in a Presidential Campaign," (Bartels, 2010). The second study reaffirmed the fundamental role of religion, socio-economic status, place of residence, and race in shaping voting behaviour. The authors wrote "In contemporary America, these conditions are best met in class, in ethnic and in ecological divisions of the population. They continue to provide, then, the most durable social bases for political cleavage." (Antunes, 2010: p. 150). Social cleavages refer to the differences in social and political values held by people of different religious, class, or ethnic groups that may influence individuals' political choices (Evans \& Ball, 2018).

According to the proponents of this model, the family has a deep impact on the political socialization of children and their attachment to a particular party. This effect is well manifested by Greenstein's (1969) classic quotation of an 11 years old Jennifer saying "all I know is we are not Republicans, my father isn't." In the words of David Denver, as quoted by Dinas (2017), it is through family socialization that people come to know about the "goodies and the baddies" in the political environment surrounding them. Thus, partisan inclinations among people precede a rational and articulate understanding of politics. The impression created on the minds of offspring by parents remains intact even after they no longer live with their parents. Research studies have established that the level of partisan similarity between offspring and parents remains fairly high and wears away slowly during offspring's adult life (p. 266).

According to the sociological model, the values and norms acquired in the early phase of life play an important role throughout the life and influence individuals' attitudes and behaviour. This model further argues that partisanship is learned by voters as part of their socialization and that voting decisions are also greatly impacted by political socialization. The social differences translate into 
political ones because each social group has its interests based on its needs and this difference in their interests plays a significant role in determining their partisanship. As social relations of different classes rarely go beyond their social standing, so they support political parties that protect their specific interests in a better way (Sharlamanov \& Jovanoski, 2014).

This approach gets hold of attitudinal (psychological) factors as dependent variables caused by the daily experiences of the individuals in social relations (Aiba, 2003). Therefore, political parties and candidates have little chance to change voters' attitudes in their favor (Visser, 1994). According to this model, the change of votes by some voters from one party to another during the election campaign or between two elections is the result of cross-pressures, (opposite forces pulling the voter in different directions) which the proponents of this model claimed to be mainly social in character arising from voters' membership in social groups having different voting inclinations (Visser, 1998). In the words of authors of the first book of Columbia team, "a person thinks, politically, as he is, socially. Social characteristics determine political preference" (Visser, 1994, p. 46).

Like class, religion also shapes people's perceptions. The difference between the two is that class shapes perception based on the redistribution of resources while religion does so on other grounds (Evans \& Ball, 2018). Having membership in a religious group is something more than just identification with this particular group. A devoted member of a religious group is supposed to take part in specific religious services and adhere to certain behavioural norms enforced through "social control or social pressure." Deviation from certain norms may lead to some consequences for the group member. Thus, there develops a link between the membership of a religious group and voting which then leads to "social predisposition" of casting votes for particular parties/candidates. Most of the religions provide for communication of these attitudinal norms by priests who also indoctrinate as to what is pious and what is sinful or profane. These priests or religious figures do not operate independently rather they are part of a "large-scale clerical hierarchy." The presence of such largescale organizations presents the explanation for uniformity among members of a specific group (Elff \& Roßteutscher, 2017, p. 202).

The common believers are not always in a position to conclude on their own about required behaviour as dictated by their religion but they receive guidance from clergymen and religiously or politically involved contacts about voting or everyday life practices and thus engage in "theology by proxy." Even if this guidance is not enough to tell the group members about their vote preferences still it will enable them to develop a kind of understanding about certain issues and thus take positions (Elff \& Roßteutscher, 2017, p. 202).

Pillarization is another phenomenon which creates linkage between members of a particular religious group and voting. Pillarization is politico-denominational segregation of a society. In other words, it means the division of society into incompatible segments grouped not only by certain beliefs and ways of life but also by segmental organizations that take care of particular groups' several aspects of life ranging from social assistance to recreational activities and thus providing for the specific groups' members "from the cradle to the grave." Pillarization can create stable patterns of denominational or religious voting but historical experiences suggest that pillarization cannot perpetuate such voting patterns permanently. For example, in the 1970s, Netherlands' three confessional parties, Catholic People's Party, Christian Historical Union, and Anti-Revolutionary Party, representing Catholics, moderate Calvinists, and orthodox and revivalist Calvinists merged into a cross-sectional party called Christian Democratic Appeal (CDA) ${ }^{1}$ (Elff \& Roßteutscher, 2017, p. 203). In Pakistan, the existence of different religious parties having their exclusive vote banks and the formation of MMA is a perfect example of politico-denominational segregation and religious parties' efforts to attract voters by allying. However, CDA is still functioning while MMA collapsed and reorganized.

Due to some shortcomings, this model gave rise to another one called the Michigan Model developed by scholars at the University of Michigan (Hutchings \& Jefferson, 2018). However, an important contribution of Lazarsfeld and his team was that by employing survey research for these studies, they demonstrated the potential of this new research technique for the study of electoral studies (Bartels, 2010).

\footnotetext{
${ }^{1}$ The merger was carried out to stop their declining popularity.
} 


\section{Psychosocial Model (Michigan Model of Voting Behaviour)}

Following Columbia School, the next important development in electoral studies came from a team of researchers at the University of Michigan (Bartels, 2010). A group of scholars at the University of Michigan, while criticizing the Columbia Model, developed an alternative model of voting behaviour known as the Michigan Model of voting behaviour (Visser, 1994). This model of voting behaviour was developed as a result of studies on 1948, 1952, and 1956 presidential elections carried out by researchers like Campbell, Kahn, Gurin, Miller, Converse, and Stokes in the Survey Research Center (SRC), the University of Michigan. The findings of these studies were compiled in the form of wellknown books like "The People Elect a President," "The Voter Decides," and "The American Voter." The theoretical work started by SRC was then taken forward by several other institutions (Antunes, 2010).

SRC's involvement in electoral studies was something accidental. In 1948, SRC surveyed on public policy issues and included one question about respondents' intentions about voting in presidential elections that year. After the election results, it emerged that the findings of the commercial pollsters about the election results proved wrong while only SRC had accurately predicted the election outcome. Later, the SRC team again returned to its sample for post-election interviews (Visser, 1994, 46) to evaluate the impact of different sociological, psychological, and political factors on vote behaviour (Bartels, 2010). The findings of this study were presented in 1952 in the form of "The People Elect a President" (Visser, 1994, 46). After this study, the SRC conducted four national surveys from 1952 to 1958 and the data was analyzed by teams of inter-disciplinary researchers. Unlike the surveys of the Columbia team, the samples for surveys conducted by the Michigan team were taken from across the country (Bartels, 2010).

The psychosocial model focuses on political factors as determinants of voting behaviour (Antunes, 2010) as it links voting decisions to the psychological predispositions of voters like their party identifications and attitudes towards the candidates, etc.(Scott \& Marshall, 2009). The model identifies six psychological factors that may influence voters' decision-making process. These factors are: (I) Party identification, (II) Concerns with issues, (III) Personal attachment to candidates, (IV) Conformity to the group standards, (V) Sense of efficacy, and (VI) Sense of civic obligation to vote. Of these six factors, party identification, candidate orientation, and issue orientation are considered to be the most important ones (Aiba, 2003). Party identification means the psychological attachment of a person with a specific political party. Issue orientation means a voter's attitude toward issues highlighted during an election campaign while candidate orientation means voters' attitudes toward the personal qualities and performance of a particular candidate (Akhter\& Sheikh, 2014).

The central theme of this model is partisanship or party identification. According to this model, partisanship is a durable association with a political party that does not necessarily mean formal registration as its member or constantly voting for it (Antunes, 2010). It argues that partisanship is the outcome of the pre-adult socialization of individuals under the influence of their parents. The scholars proposing this model argued that individuals develop partisanship under parental influence just like their acquisition of religious beliefs. For substantiating this claim, they claimed that the survey data showed that an overwhelming majority of their respondents were likely to identify themselves with parties with which their parents identified themselves (Hutchings \& Jefferson, 2018).

The psychological model, while also recognizing the importance of social factors, argues that social characteristics in a given population do change but very slowly and over a long period but the changes in voting patterns occur from one election to another. According to this model, these oscillations in election results within a short period cannot be attributed to independent variables (social factors) which almost remain the same during the time during which there occurs huge fluctuation in voting patterns. Thus, the psychological model looks at this change in voting trends as the result of political factors like issues and candidates that change in a short time (Akhter\& Sheikh, 2014).

The argument which the American Voter presented was that voters' attitudes about issues, candidates, and political parties were factors that subsequently predicted voters' choices. The book further argues that the intensity of partisanship of voters could determine their assessment of the candidates and position on issues (Hutchings \& Jefferson, 2018) and thus voting decision. 


\section{Partisanship}

As stated earlier, the central theme of this model is partisanship or party identification. Party identification is the durable attachment with political parties which starts in the early phases of political socialization (Dinas, 2017). According to this model, party identification is a sense of psychological attachment with any political party like sense of attachment with one's social class, religious, or racial group (Hutchings \& Jefferson, 2018). Party affiliation, like religious affiliation, often originates within the family (Thomassen \& Rosema, 2009) but is also influenced by attitudes and values of colleagues and peers (Antunes, 2010). In the words of Campbell and his colleagues at the University of Michigan, party identification means "the sense of personal attachment which the individual feels towards the party of his choice" (Thomassen \& Rosema, 2009, p. 43). According to this argument, voters have a long association with political parties without any regard to candidates or issues in specific elections. Voters may occasionally defect from their parties and vote for other candidates but usually, they return to the party with which they feel a sense of attachment (Bowler, 2018). Thus, partisanship progresses as a mode of identity, embedded in people's early socialization and operating as a perceptual screen of simultaneous political attitudes (Dinas, 2017).

This model's central idea is that voters' evaluation of candidates in elections is mainly guided by their psychological sense of attachment to a political party (Green \&Baltes, 2017). It argues that partisanship provides shortcuts to voters due to which they require less amount of information to process. They don't need to take pains in understanding complex ideological and issue positions as political parties provide them cues about them (Bowler, 2018). Partisanship provides simple and important signals to voters while making complex political decisions (Bonneau \& Cann, 2013).

According to psychosocial theory, party identification becomes part of the identity of voters like their national identity. It argues that just as people are identified as Americans, Germans, and Macedonians, so they are also identified about particular parties like Liberals, Conservatives, Socialists, and Liberal Democrats etc. (Sharlamanov \& Jovanoski, 2014). The authors of The American Voter wrote that;

Few factors are of greater importance for our national elections than the lasting attachments of tens of millions of Americans to one of the parties. These loyalties establish a basic division of electoral strength within which the competition of particular campaigns takes place. (Campbell et al. 1960, 121).

According to the Michigan model, partisanship is fairly stable but not unchanging (Bartels, 2010). The proponents of this model point out two factors for any such changes: personal forces and social forces. Personal forces are changes in voter's social environment and exclusively depend on voters' circumstances (Hutchings \& Jefferson, 2018) such as joining higher education institutions, contracting marriage, shifting to a new area of residence, or switching one's job etc. (Antunes, 2010). Social forces involve experiences that are shared by a large number of people within the society (Hutchings \& Jefferson, 2018) like the Fascist Government's end in Portugal, joining of the European Union, or disintegration of the former Union of Soviet Socialist Republics (USSR). Between the two, the changes of the former type occur comparatively frequently but it is the later types that have a faster and deeper impact on electoral trends (Antunes, 2010).

Some scholars questioned some of the aspects of party identification theory and introduced its revisionist view. According to this new theorization of party identification, it is neither rooted in identity-forming experiences nor does it result in fixed political preferences. Instead, party identification is formed slowly in the light of recurrent experience with parties. According to this view, voters retrospectively assess the government's performance and thus reach their conclusions. This new version of party identification further argues that individuals add new information to their existing experiences with political parties and their stances on different issues, so changes in their opinions with changes in the profiles of political parties become not only possible but likely. Thus, policy stances of parties and issues become more important here than socialization experiences. In other words, in this new version of party identification, the present does matter as much as the past or even more, and thus continuity and change co-exist (Dinas, 2017). Proponents of this version argue that partisanship attitude reflects an individual's judgment of parties' performance on issues important for the individual (Ahmad, 2010).

This model's argument of stable and lasting partisanship has been challenged by many researchers who claim that the relationship between individuals and political parties in the US and 
Europe is progressively fading. Model's inability to explain the logic as to how some voters who identify themselves with one party can vote for another party also invites criticism from its critics (Antunes, 2010).

Another major criticism of this model is that if party identification can influence voters' positions on issues and their evaluation of candidates, then these very factors can also influence party identification of voters. The proponents of this model, however, reject this criticism on the ground that voters generally lack ideological sophistication and political knowledge and that partisanship develops during adolescence and happens to be stable as compared to candidate and issue evaluation which usually develop at a later stage and also happen to be temporary. For changes in presidential election results in a short period without corresponding redistribution of partisanship, Philip Converse, one of the authors of The American Voter, presented the concept of "short-term deviations from the normal vote." By this term, he meant the impact of short-lived circumstances like scandals or international issues on election results (Hutchings \& Jefferson, 2018, p. 25).

Most of the claims made by the authors of "The American Voter" were replicated by scholars more than 50 years after the publication of the original work and were published as "The American Voter Revisited." The later proponents of the Michigan Model argue that partisanship should be looked at from the viewpoint of 'Social Solidarity Theory.' In other words, they argue that party identification should be considered as a social identity (Hutchings \& Jefferson, 2018).

\section{Issue and Candidate's Orientation}

Other important components of this model are issue orientation and candidate orientation (Aiba, 2003). It means voters' attitudes toward issues and candidates (Akhter\& Sheikh, 2014). Issue voting mostly takes place during times of socio-economic disorder when political parties provide relatively different policy alternatives (Carmines \& Stimson, 1980).

There are two different types of issue voting: hard issues and soft tissues. The first one involves a careful analysis of issues raised by parties. Voting decisions in this type of issue voting are the result of sophisticated calculus on the part of voters. Hard issue voting represents a conscious attempt by voters to use policy choices for making their final voting decisions. The voters, after thorough evaluation of policy preferences of various parties/candidates in a given election, vote for the parties/candidates who are nearest to them in terms of issue space. Hard issue voting is better exemplified by those who have cognitive skills. The second type, easy issue voting, takes place when an issue becomes so entrenched over a long time that it shapes "gut responses" of voters to different parties and candidates. This type of issue voting does not require conceptual sophistication (Carmines \& Stimson, 1980, p 80). In Pakistan, the anti-corruption slogan of PTI is a good example of easy issues.

It may be noted that political parties do not always need to take opposite stances to each other on every issue as there are many issues on which the opposite stance is not possible. For example, reducing the crime rate, eradication of corruption, and protecting the environment are issues on which everyone agrees (Brug, 2017). These are called valence issues and they are the issues where all voters want the same thing. On such issues, the least difference is found in candidates' promises though they may disagree on their strategies for achieving the goals. In such circumstances, the voters have to select their candidates on some other criteria like the level of voters' trust in candidates and their past performance. Candidates' vote also plays an important role in such a situation (Dowding, 2018).

Thus, parties prioritize some issues over others. As confrontation between parties on issues is not always the case, so parties emphasize issues on which they have a good reputation and deemphasize others. It was based on these findings that the concept called "Saliency Theory of Party Competition" was developed by scholars. According to this theory, every competing party has certain policy issues to "own" (policy areas in which it has a comparatively good reputation). Political parties expect gaining electoral support by highlighting the salience of "their" issues while campaigning for election, and thus see an incentive in constantly emphasizing these issues. In the West, it has been established through empirical studies that the salience of specific types of issues during election campaigns do influence aggregate election results (Brug, 2017, 522).

By prioritizing certain issues, according to Petrocik (1996), parties give signals to the electorate that they are more sincere, committed, and in a better position to address these issues (Petrocik, 1996). This prioritization of some policy issues by parties is called "issue ownership." It means that voters do link specific issues with certain parties and thus these parties become those 
issues' owners. The voters, while deciding about vote choice, think about issues that dominate election campaigns (Brug, 2017, 522). Looking at the political landscape of Pakistan, it is noticed that different parties own different issues. For example, PTI's most important slogan is the anti-corruption drive, PPP highlights its pro-poor policies, and PML-N focuses on its achievements in the fields of communication and economic growth, politico-religious parties promise to enforce sharia, while ANP highlights its stance about secularization and provincial autonomy.

\section{Rational Choice Model of Voting Behaviour}

The third and last model of voting behaviour is the Rational-Choice Model which tries to explain individuals' voting behaviour in economic terms (Antunes, 2010). This model claims that individuals' voting behaviour is an outcome of cost-benefit analysis. The voters, it argues, before casting votes, critically evaluate issues highlighted and policies supported by various political parties and candidates (Scott \& Marshall, 2009).

The most influential introducers of Rational Choice Theory in electoral studies were economists Anthony Downs, Duncan Black, and Kenneth Arrow. Anthony Downs' seminal book (An Economic Theory of Democracy) is considered as the foundational work for engaging the Rational Choice Model for the study of voting behaviour (Klingelhofer, 2010). In this book, Downs argues that voters would assess candidates and their electoral platforms and would vote for the party based on promises it made to deliver (Stegmaier, Lewis-Beck \& Park, 2017). Proponents of this model argue that voters adjust their affiliation with political parties during every election while keeping in view economic conditions and political parties' approach to them (Antunes, 2010). It further claims that voters cast votes for parties and candidates whose policy positions are closest to them (voters). Thus, voters keep in mind their interests while deciding to vote for a party or candidate and these interests may be personal or related to family, class, or group etc. (Dowding, 2018).

The premise of this model is that if the functioning of the market can be explained with rational choice assumptions then they can also be applied to the explanation of the political system. The theory establishes an analogy, between consumers and voters on the one hand, while on the other hand, between enterprises and political parties. It argues that just like enterprises that want to maximize profits and consumers who desire to maximize their utility, political parties struggle to maximize electoral gains and voters seek to maximize their votes' utility (Antunes, 2010). Downs expressed this point in the following words;

Our main thesis is that parties in democratic politics are analogous to entrepreneurs in a profit-seeking economy. So, to attain their private ends, they formulate whatever policies they believe will gain the most votes, just as entrepreneurs produce whatever products they believe will gain the most profits for the same reason. To examine the implications of this thesis, we have assumed that citizens behave rationally in politics. This premise is itself a second major hypothesis (Downs, 1957, pp. 295-96).

Downs further argues that neither political parties nor the voters are interested in ideologies. According to him, ideologies, for parties, are means for getting votes while for voters, ideologies are means to reduce costs of political information. Voters simplify the choice between parties because they do not need to get thorough information about a party's potential activities if it came into power. They, instead, can identify a party's idea of a good society and their place in that society. So, it can be said that the ideological positions of candidates or parties are kind of "heuristics" (Elff, 2018, p 138).

There are three main points of this model. (1) All decisions made by voters and political parties are rational as they are steered by self-interest and aimed at maximization of their actions' utility. According to this model, parties contest elections not due to altruistic motives, but to control power through which they will then secure gains and prestige. Downs writes, "Upon this reasoning rests the fundamental hypothesis of our model: parties formulate policies to win elections, rather than win elections to formulate policies" (Downs, 1957, p. 28) (2) Voters and parties are responsible and trustworthy actors, so consequences of their decisions are predictable as there is a level of consistency in the democratic system. According to Downs, voters compare the expected results from both voting for the government and the opposition. In case they expect more from the government party, they will vote for it. But in case they expect less from it then they will vote for the party in opposition. However, if they expect no difference in results from the two parties, they will not vote. (3) The democratic system assumes a level of uncertainty (Antunes, 2010). It means a lack of information about the course that events take. This uncertainty is manifold and may be found in any stage of the 
political decision-making process and usually has an impact on both the voters and political parties as it controls the level of confidence with which the two make decisions (Downs, 1957).

\section{Retrospective vs Prospective Voting}

Within economic voting, there emerges the question of perspective and retrospective voting. It means whether voters assess parties' past performance (retrospective voting) or they vote with future expectations from the party (prospective voting). Most of the studies answering this question show the retrospective economic voting to be dominant (Stegmaier, Lewis-Beck \& Park, 2017).

\section{Pocketbook vs Sociotropic Voting}

Another important question concerning economic voting is whether people prefer their gains or improvement in national economic conditions. Studies conducted in the US, Denmark, and other countries show that most of the voters give preference to economic matters related to the national economy (sociotropic)rather than pocketbook considerations (Stegmaier, Lewis-Beck \& Park, 2017).

\section{Strategic Voting}

As the voters are rational actors, so they do not always vote for the candidate/party that they prefer the most. Sometimes, they go for strategic voting which means that they vote for a party which is not their favorite, but voting for it produces better results than voting for their priority. For example, there is a small party that does not have enough chances of winning the contest. The voters who consider it as their priority will vote for their second priority party to avoid wastage of their votes (McGann, 2016) (as their preferred party does not have fair chances of winning the election). In other words, strategic voters deviate from their most preferred choice on the ballot list simply because the victory of a less preferred choice may better realize their expectations about possible benefits. They combine their candidate preference and their expectations that a particular party/candidate will win the election. A strategic voter votes for a less preferred choice if that choice has a high chance of electoral success (Gschwend \& Meffert, 2017).

According to Downs, predicting other voters' preferences is an important part of voters' decision-making process. He writes that "[e]ach citizen uses his forecast to determine whether the party he most prefers is a part of the relevant range of choice. If he believes it is not, then rationality commands him to vote for some other party" (Downs, 1957, p. 48). Downs adds that a rational voter first decides as to which party will benefit him the most and then tries to assess whether that particular party has any chances of winning elections. He writes that voters do so because they want their votes to be among those that select the government rather than mere expression of preferences (Downs, 1957).

\section{Conclusion}

Voting behaviour is a complex phenomenon, and it is difficult to explain its determinants in absolute terms. Social scientists have the difficult and challenging task of coming up with explanations and searching for the determinants of social and political decisions made by agents. As social and political agents constantly change and so are the conditions in which they are bound to operate, therefore, approaches and explanations of political and social behaviour also vary. As discussed in this paper, no single theoretical model can claim to be the only explanation of voting behaviour. Each approach provides a broader sketch of how different factors influence voters' decision-making process. In different contextual conditions, one or the other model may be more relevant. If manageable, a mixedmethods approach may always provide a better understanding of the voting behaviour. In the study of voting behaviour in Pakistan, the political environment is so diverse that all aforementioned three models have their strengths and relevance. The principal author of the paper is trying to develop a clear understanding of the voting behaviour in the district of Swabi, Khyber Pakhtunkhwa, using these models. The case study and application of these models will further broaden our understanding of how a mixed-method approach may be a better option than deploying a reduced or narrower approach.

\section{References}

Aiba, J. (2002). Reviewing the Theories of Voting Behaviour. Memoirs of Nara University, No 31, 283-304.

Antunes, R. (2010). Theoretical models of voting behaviour. Exedra, 4, 145-70.

Antwi, R. B. (2018). How do voters decide? A study of the determinants of voting behaviour in Ghana. (Unpublished Master thesis). Wright State University, Dayton, USA. 
Bartels, L. M. (2010). The Study of Electoral Behaviour. In J. E. Leighley (Ed.), the Oxford Handbook of American Elections and Political Behaviour (pp. 239-261). Oxford, UK: Oxford University Press.

Berelson, R. B., Lazarsfeld, P. F. \& McPhee, W. N. (1954).Voting: A Study of Opinion Formation in a Presidential Campaign. Chicago: University of Chicago Press.

Dinas, E. (2017). The Evolving Role of Partisanship. In K. Arzheimer, J. Evans, \& M. S. Lewis-Beck (Eds.), the SAGE Handbook of Electoral Behaviour, Vo. 1 (pp. 265-86). London: SAGE Publications.

Downs, A. (1957). An economic theory of democracy. New York: Harper Collins Publishers.

Evans \& Ball. (2018). Long-term factors: class and religious cleavages. In J. Fisher, E. Fieldhouse, M. N. Franklin, R. Gibson, M. Cantijoch, \& C. Wlezien (Eds.), The Routledge Handbook of Elections, Voting Behaviour, and Public Opinion (pp. 123-35). Abingdon: Routledge.

Elff, M. \& Roßteutscher, S. (2017). Religion. In K. Arzheimer, J. Evans, \& M. S. Lewis-Beck (Eds.), the SAGE Handbook of Electoral Behaviour, Vo. 1 (pp. 199-219). London: SAGE Publications.

Elff, M. (2018).Ideology and electoral choice. In J. Fisher, E. Fieldhouse, M. N. Franklin, R. Gibson, M. Cantijoch, \& C. Wlezien (Eds.), The Routledge Handbook of Elections, Voting Behaviour and Public Opinion, (pp.136-45). Abingdon: Routledge.

Gschwend, T. \&Meffert, M. F. (2017).Strategic Voting. In K. Arzheimer, J. Evans, \& M. S. LewisBeck (Eds.), the SAGE Handbook of Electoral Behaviour, Vo. 1 (pp. 339-66). London: SAGE Publications.

Hutchings, V. L. \& Jefferson, H. J. (2018).The sociological and social-psychological approaches. In J. Fisher, E. Fieldhouse, M. N. Franklin, R. Gibson, M. Cantijoch, \& C. Wlezien (Eds.), The Routledge Handbook of Elections, Voting Behaviour, and Public Opinion (pp. 21-29). Abingdon: Routledge.

McGann, A. (2016). Voting choice and rational choice. In Oxford Research Encyclopedia, Politics. Retrieved from https://pdfs.semanticscholar.org/01c2/2f66e3d7c9282c6e50bf9330397a0d864 50d.pdf

Scott, J., \& Marshall, G. (Eds.). (2009). A dictionary of sociology (Eds.). Oxford: Oxford University Press.

Sharlamanov, K. \& Jovanoski, A. (2014).Models of Voting. International Refereed Research Journal, V, (1), 16-24.

Stegmaier, M., Lewis-Beck, M. S., \& Park, B. (2017). The VP-Function: A Review. In K. Arzheimer, J. Evans, \& M. S. Lewis-Beck (Eds.), the SAGE Handbook of Electoral Behaviour, Vo. 2 (pp. 584-605). London: SAGE Publications.

Visser, M. (1994). The Psychology of Voting Action: On the Psychological Origins of Electoral Research, 1939-1964. Journal of the History of the Behavioural Sciences, 30, 43-52.

Visser, M. (1998). Five theories of Voting Action: Strategy and Structure of Psychological Explanation. (Ph.D. Dissertation). Universiteit Twente, Enschede, Netherlands. 